\title{
EROSÃO COSTEIRA NO MUNICÍPIO DE BARRA DE SANTO ANTONNIO, LITORAL NORTE DE ALAGOAS
}

\author{
Coastal erosion in the municipality of Barra de \\ Santo Antônio, north coast of Alagoas
}

\author{
José Ferreira dos Santos Júnior, Eduardo Machado Menezes Araujo, Bruno Ferreira \\ Instituto de Geografia, Desenvolvimento e Meio Ambiente, Universidade Federal de Alagoas \\ *Autor para correspondência: junioratrio@hotmail.com
}

\begin{abstract}
RESUMO
Os ambientes costeiros configuram mosaicos bastante dinâmicos em constante transformação, com equilíbrio muito tênue em relação a modificações. De um modo geral, a ocupação do pós-praia e a retirada da vegetação rasteira acarretam mudanças na morfodinâmica, processos que foram identificados no município de Barra de Santo Antônio, no litoral norte de Alagoas. Para analisar esses processos foram utilizados geoindicadores, identificados em campo, o que possibilitou a caracterização e setorização dos processos mapeados. Foram delimitados oito setores, classificados segundo a tendência erosiva e/ou intensidade de processos já iniciados. A metodologia mostrou-se promissora, fornecendo dados que poderão ser refinados em estudos futuros. Dessa forma, o presente estudo visou à oferta de dados que possam auxiliar os gestores e órgãos competentes na tomada de decisão, bem como chamar a atenção para esse tema no município, estimulando ações e discussões sobre o planejamento territorial no processo de ocupação e uso das terras.
\end{abstract}

Palavras-chave: linha de costa, Barra de Santo Antônio, dinâmica costeira, morfodinâmica praial.

\section{ABSTRACT}

Coastal environments configure very dynamic mosaics in constant transformation, with a quite tenuous equilibrium when it comes to its modifications. In general, post-beach occupation and 
the removal of its vegetation causes changes in the morphodynamics. Processes that were identified in the municipality of Barra de Santo Antonio, in the North Coast of Alagoas. To analyze these processes were used geoindicators, identified in the field, which allowed the characterization and sectorization of the mapped processes. Eight sectors were delimited, classified according to the erosive tendency and/or intensity of the processes that has already started. The methodology is showed promising, providing data that could be refined in future studies. Thus, the present study aimed at providing data that can assist managers and competent bodies in decision making, as well as draw attention to this theme in the Municipality, stimulating actions and discussions on territorial planning in the land occupation and use process.

Keywords: coastline, Barra de Santo Antônio, coastal dynamics, beach morphodynamics.

\section{INTRODUÇÃO}

Os sistemas costeiros constituem ambientes transicionais com grande dinâmica de processos, dadas a sazonalidade de seus estados médios e a capacidade de reconfiguração ambiental. Essas variações fazem com que esses ambientes sofram mudanças constantes em sua morfologia, a exemplo dos retrabalhamentos da linha de costa. A erosão costeira é uma das principais responsáveis por esses rearranjos morfológicos, sendo o resultado do balanço de processos de acreção e denudação naturais que atuam sobre as feições costeiras. Esses processos são regulados pelas taxas de sedimentação, fortemente influenciadas por processos continentais, e pela ação da hidrodinâmica do marinho raso. Outro aspecto importante é a observação da ocupação e dos usos das terras na zona costeira, principalmente quando associados a processos desordenados ou que não levaram em consideração a morfodinâmica local, o que pode desencadear uma reorganização e/ou modificação do balanço morfodinâmico, contribuindo para a reconfiguração da linha de costa e suas morfologias associadas.

Do ponto de vista ambiental, os ecossistemas costeiros são ambientes influenciados por processos continentais e marinhos, que interagem através de variáveis físicas, químicas, biológicas, climáticas e antrópicas, as quais se inter-relacionam de maneira complexa tendendo ao estabelecimento de um equilíbrio dinâmico (Souza, 2001). A erosão costeira é um processo natural, desencadeado e regulado por leis físicas, que, ao longo do Quaternário, ajudou a modelar as linhas de costa atuais. No entanto, os processos de ocupação e ações humanas nesses ambientes têm levado ao desencadeamento de erosão e retrabalhamentos acelerados das feições costeiras (Nicolodi, 2008).

Não obstante a elevada instabilidade ambiental das zonas costeiras, a erosão ainda está associada a crescentes taxas de ocupação da faixa litorânea, em função de uma grande valorização e exploração imobiliária das orlas marítimas (Mota \& Souza, 2018). Nesse contexto, a erosão costeira é um processo natural que vem sendo acelerado por causas antrópicas, podendo se tornar um problema socioeconômico, ocasionando a perda de patrimônio privado e espaços públicos (Morais et al., 2008). Daí a importância de se entender como esses processos vêm sendo desencadeados, suas causas e como podem afetar as regiões costeiras. 
Em praias arenosas, muito comuns no Nordeste brasileiro, a linha de costa constitui um espaço utilizado pelo homem para diversos fins, destacando-se aqueles de natureza recreacional e turística (Mazzer, 2007). Em Alagoas, a maior parte do litoral é fortemente utilizada como área de recreação e lazer, com destaque para a capital Maceió, destino turístico bastante conhecido e que vem atraindo turistas todos os anos para suas praias.

Ao se realizar um levantamento em bibliografias, documentos oficiais e periódicos científicos sobre erosão costeira em Alagoas, observa-se que são recorrentes os relatos sobre esses processos nas praias do estado. Quanto às causas, os diversos estudos consultados apontam como principal o grande aumento populacional na zona costeira a partir da segunda metade do século XX. Nessas áreas, a ação antrópica por meio da ocupação próximo à linha de costa vem intensificando o retrabalhamento das feições praiais.

Ao discutir a erosão costeira em áreas densamente ocupadas, Muehe afirma que:

É nessas áreas de maior ocupação que a erosão costeira se torna uma preocupação sendo frequentemente agravada pela interferência do homem por meio de construções de estruturas que bloqueiam o trânsito livre de sedimentos, como, por exemplo, na estabilização de desembocaduras fluviais, na construção de instalações portuárias ou para fixação da linha de costa (p. 97, 2005).

Outro aspecto importante ao se discutir a erosão costeira no Brasil, em escala municipal, como o presente estudo se propõe, é a falta de dados e estudos mais aprofundados, dificultando um maior entendimento na geração proposta, que possam auxiliar os gestores na minimização desses processos na linha de costa. A busca pela identificação das possíveis causas da erosão costeira no Brasil tem constituído um desafio, muitas vezes um exercício árduo, uma vez que faltam elementos e dados mais robustos para embasar os estudos (Muehe, 2005).

Mazzer, ao discutir a importância de se estudar a linha de costa, mapeando sistematicamente suas alterações ao longo do tempo, afirma que:

O mapeamento sistemático da linha de costa e o acompanhamento de suas mudanças ao longo do tempo representam ferramentas para a geração de informações de grande valor para o planejamento e gerenciamento costeiro, pois fornecem subsídio para o estabelecimento de faixas de recuos (setback) da zona litorânea, permitem a determinação para a implantação de obras de intervenção direta na linha de costa (guias correntes, molhes, engordamento de praia etc.) (p. 37, 2007).

A erosão costeira, além de modelar a linha de costa, traz consigo impactos que afetam a dinâmica natural e antrópica da região, através das variações que ela possa passar no decorrer dos anos. Entre os problemas encontrados, estão a redução de áreas emersas, fortemente ligadas ao processo de construção histórica, o que leva a danos diretos ao patrimônio material, a depreciação do potencial turístico e urbanístico, além da necessidade de elevados gastos, principalmente na construção de obras estruturais de proteção da costa em amplos trechos de praia (Martins et al., 2016).

Segundo Mazzer (2007), as orlas marítimas representam unidades geográficas especialmente vulneráveis a fenômenos naturais ou potencializados, ligados à morfodinâmica costeira. São processos erosivos e/ou de acreção praial, inundação, ventos intensos, marés 
meteorológicas, entre outros. Entender seu funcionamento e estágios médios de equilíbrio contribui para a geração de informações que possam ajudar no planejamento, na regulação e na tomada de decisões pelos órgãos competentes, além de contribuir cientificamente com a discussão dessa temática, nesse caso específico, no município de Barra de Santo Antônio.

O município de Barra de Santo Antônio (Figura 1) está localizado na Região Metropolitana de Maceió, em sua porção norte. Nos últimos anos vem passando por um retrabalhamento da sua linha de costa, notadamente em sua porção urbana, próximo à sede municipal. Isso pode ser facilmente constatado na paisagem, onde em 2011 foi instalada uma estrutura de contenção da erosão, bagwall (dissipador de energia), devido ao agravamento da abrasão marinha sobre as propriedades e construções presentes na linha de costa. Essas áreas estavam sendo fortemente afetadas pela oscilação sazonal de marés, principalmente nas marés de sizígia, trazendo insegurança aos moradores, comerciantes e turistas.

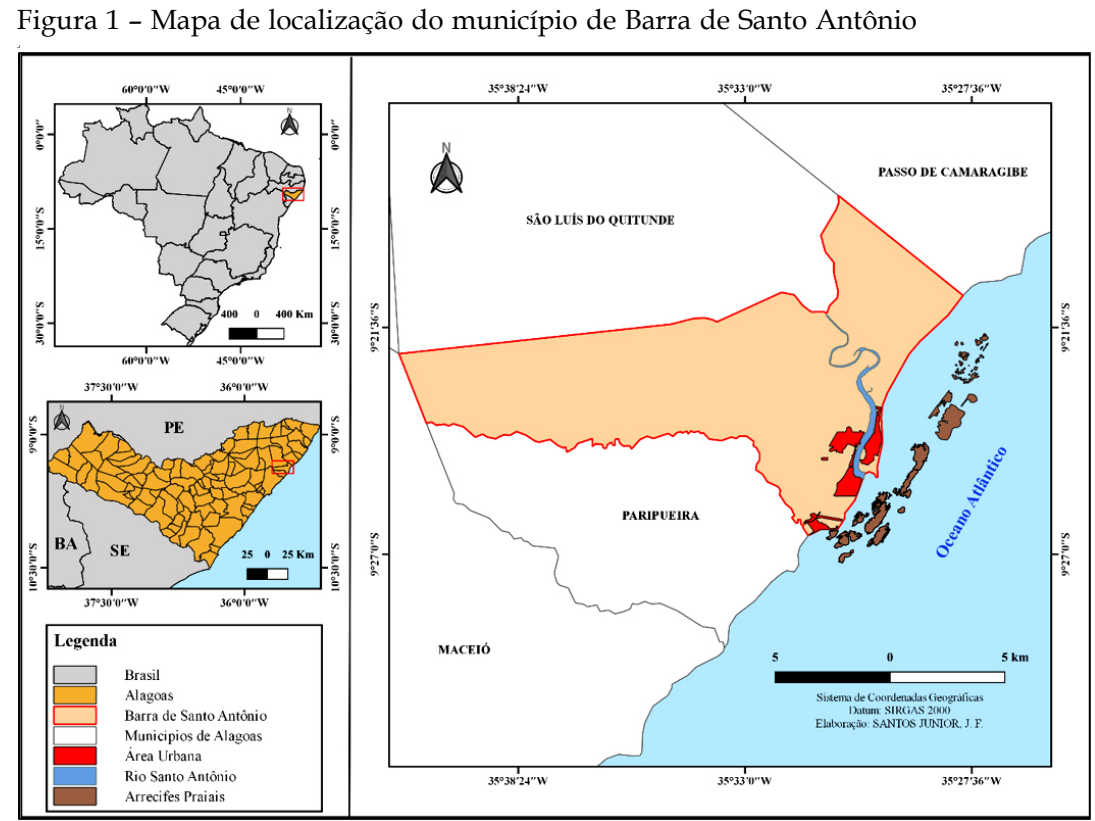

Fonte: elaborado utilizando-se a base cartográfica do IBGE (2017).

A avaliação das configurações das praias naturais e o registro de processos acelerados de erosão, principalmente aquelas com a presença de obras estruturais de proteção costeira, constituem geoindicadores que podem contribuir com informações para o estudo do retrabalhamento dessas áreas. A presença desses geoindicadores associados a obras estruturais de contenção da erosão costeira podem levar a uma situação em que as praias se tornem em menos atrativas para o turismo (Anfuso et al., 2014).

Identificar e caracterizar esses geoindicadores na zona costeira do município de Barra de Santo Antônio constitui o objetivo do presente estudo. Esses dados servirão como variáveis na caracterização e classificação da erosão costeira no município, contribuindo na busca pelo entendimento das causas e do funcionamento dos processos de retrabalhamento das linhas de costa atuais. Nesse contexto, o presente trabalho teve como objetivo identificar e classificar, através de geoindicadores, a presença ou ausência de erosão costeira no município de Barra de Santo Antônio, mapeando, setorizando e classificando os conjuntos identificados. 


\section{MATERIAIS E MÉTODOS}

Os geoindicadores de erosão costeira e seus estudos ajudam o monitoramento de áreas suscetíveis a esses processos, onde sua identificação auxilia os gestores públicos na melhoria do planejamento territorial em toda a sua linha de costa. A realização de análises dos processos da evolução do ambiente praial, a médio e a longo prazo, pode fornecer as informações necessárias para a identificação da distribuição espacial e do grau de vulnerabilidade de uma praia (Silva et al., 2016). Ao abordar esse tema, Silva et al. (2016) afirmam que:

A definição e a quantificação do grau de vulnerabilidade à erosão costeira, permite a identificação de áreas sujeitas e ação de ventos de elevada magnitude, como ressacas e marés de sizígias, os quais de traduzem em riscos a população, com energia suficiente para transformar/destruir porções significativas de espaços naturais e/ou antropizadas.

Para a identificação e classificação da erosão costeira, foram utilizados 12 geoindicadores (Figura 2). Essa metodologia foi construída com base em outros estudos que utilizaram geoindicadores, a exemplo de Souza (2009) e Martins et al. (2016), adaptando os parâmetros de avaliação da linha de costa para a realidade do município estudado. Os parâmetros foram agrupados em quatro classes, cada uma com três conjuntos de geoindicadores, cuja classificação adotada está descrita a seguir: muito baixa, baixa, processos erosivos moderados e processos erosivos avançados.

Os procedimentos operacionais (Figura 3) foram divididos em 4 etapas: revisão bibliográfica e cartográfica, processamento de dados, trabalhos de campo e redação do texto. A sequência está apresentada no organograma a seguir:

Figura 3 - Fluxograma das etapas metodológicas

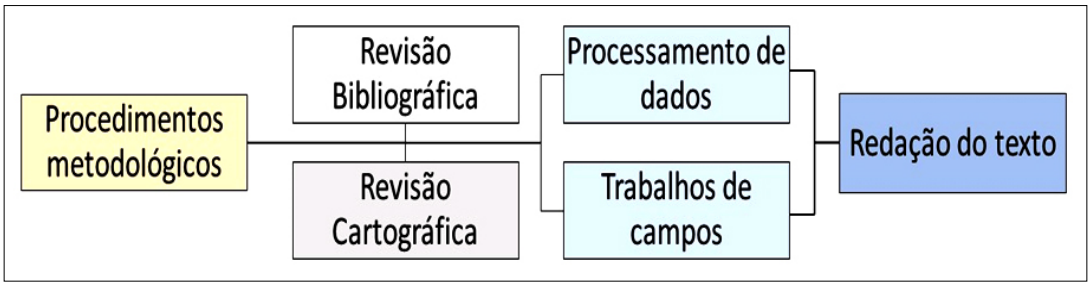

Fonte: Santos Junior (2019).

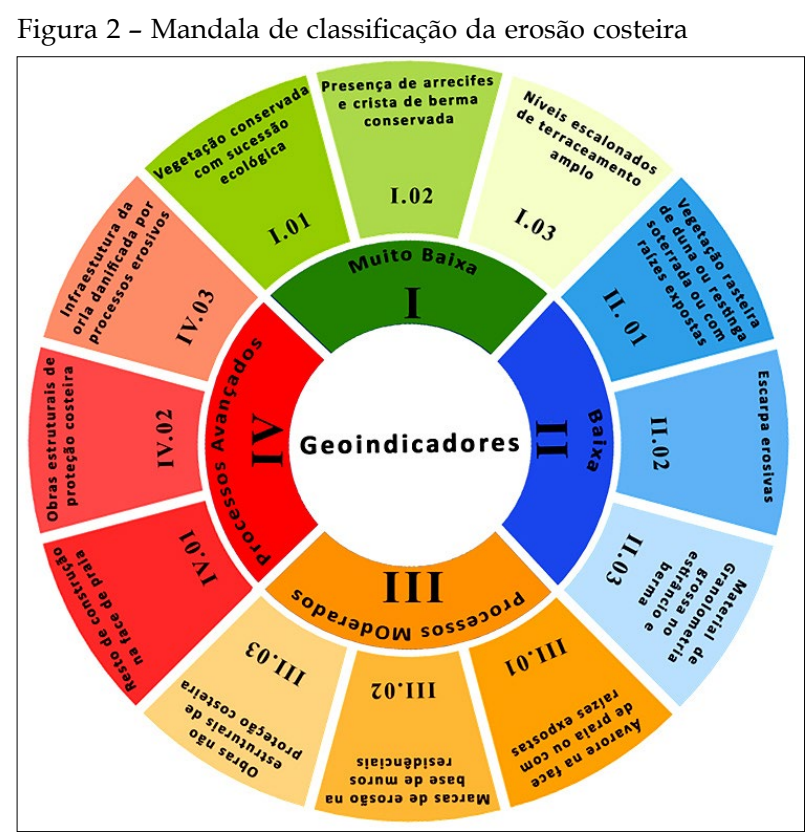

Fonte: adaptada de Souza (2009) e Martins et al,. (2016). 


\section{RESULTADOS E DISCUSSÕES}

Os resultados obtidos mostram que a linha de costa do município de Barra de Santo Antônio vem passando por intensas modificações derivadas da intensificação dos processos morfodinâmicos e retrabalhamento das morfologias estruturadas sobre os terraços arenosos praiais (Figura 4). Os geoindicadores mapeados mostram que essas transformações têm sido bem mais intensas quando associadas aos processos de uso e ocupação das terras, levando à potencialização de processos naturais e consequentes prejuízos econômicos, culturais e sociais.

Setor 1 - Localizado na porção extremo norte da área, recebia grandes concentrações de visitantes por conta de sua beleza cênica. Foram identificados os geoindicadores de Níveis escalonados de terraceamento amplo (I.03) e Árvores na face de praia com raízes expostas (III.01). Com base nesses geoindicadores, este setor foi classificado em duas categorias: tendência muito baixa e baixa erosão. Essas tendências vêm se consolidando em parte pelas dificuldades de acesso, agravadas pelo fechamento de antigas estradas em propriedades privadas, o que reduziu significativamente a visitação nessa porção nos últimos anos.

Setor 2 - Foi classificado com tendência erosiva muito baixa. Todo este setor se localiza distante da área urbanizada, não tendo a ação humana como fator de desequilíbrio desse ambiente. Sua vegetação encontra-se com sucessão ecológica conservada, o que ajuda a fixar e manter os sedimentos depositados, corroborando com o equilíbrio praial. Em todo este setor foram Figura 4 - Mapa dos geoindicadores, setores e intensidade erosiva
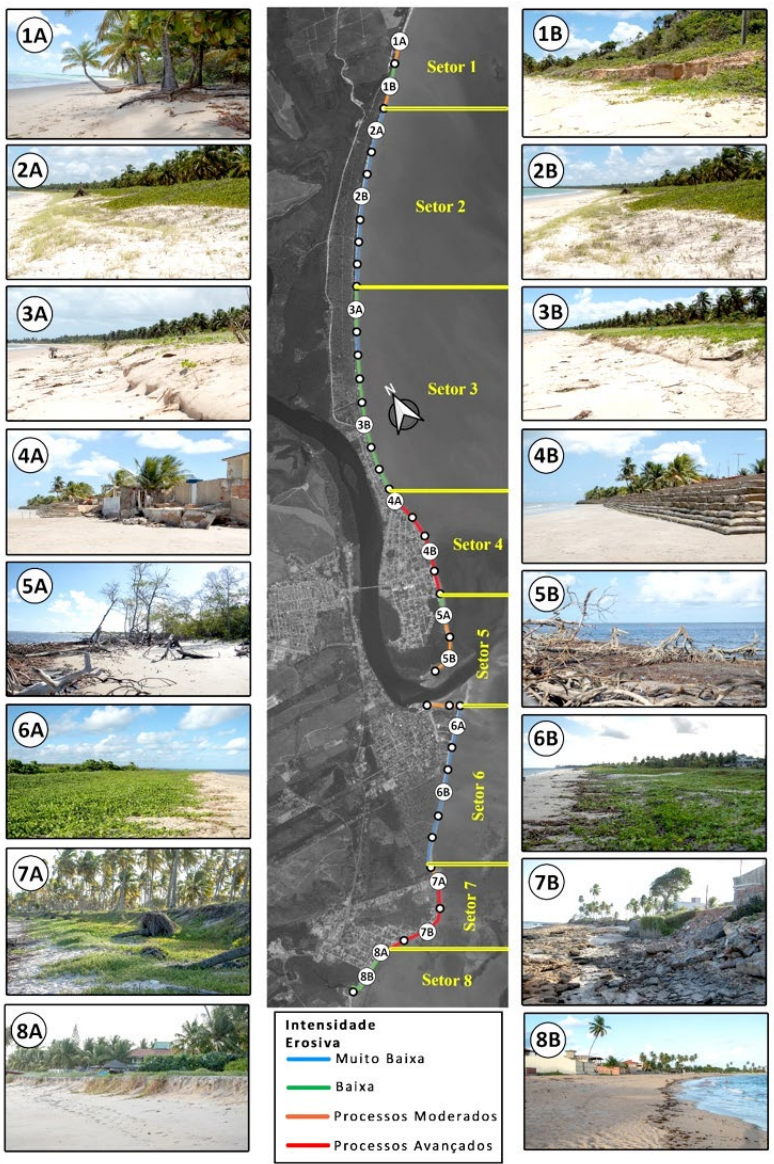

Fonte: Santos Junior (2019). encontrados geoindicadores, como a Vegetação conservada com sucessão ecológica (I.01), Níveis escalonados de terraceamento amplo (I.03) e presença de pós-praia conservada.

Setor 3 - Apresenta classificação muito baixa e baixa, com predominância da segunda. Este é o maior setor em extensão, por estar mais próximo de algumas áreas com construções. Já apresentam geoindicadores mais intensos, contendo em toda sua extensão Escarpas erosivas (II.02) que podem ser identificadas como um princípio de processo erosivo; contudo, a vegetação ajuda a manter o equilíbrio, sendo pouca a representatividade erosiva nesta área, servindo como alerta para a importância de sua conservação. 
Setor 4 - Tem como característica a grande concentração de construções residenciais e, consequentemente, grande circulação de pessoas em sua extensão. Este setor apresenta uma das piores situações do município. Em 2011 foi construído um bagwall (dissipador de energia), por conta do aumento de ocorrências em relação à perda do patrimônio público e privado pela erosão intensa, uma tentativa de minimizar as perdas que eram constantes. Os geoindicadores encontrados foram os de Marcas de erosão na base de muros residenciais (III.02), Obras não estruturais de proteção costeira (III.03) e Obras estruturais de proteção costeira (IV.02), sendo, assim, o setor classificado na categoria de processos erosivos avançados em toda a sua extensão.

Setor 5 - Apresenta um variado leque de interferências antropogênicas em ocorrência, como desmatamento de manguezais que estão próximo à praia para a extração irregular de madeira. Este setor está localizado próximo à foz do rio Santo Antônio, onde foram encontrados o geoindicador Árvore na face de praia ou com raízes expostas (III.01), uma pequena faixa ainda de restinga e partes com as raízes expostas de árvores do manguezal, enquadrando-se como área com processos moderados de erosão. Apesar de $a$ priori receber maior aporte sedimentar e possuir arrecifes que ajudam a dissipar parte da energia das ondas.

Setor 6 - Situa-se na outra margem do rio, ao sul, próximo à praia de Tabuba, que dá nome ao povoado, apresentando ocupação relativamente adensada, mas a cerca de $500 \mathrm{~m}$ de distância da linha de costa. Apresenta classificação como de processos moderados na foz e tendência muito baixa no restante do setor mais ao sul. Foram identificados os geoindicadores Vegetação conservada com sucessão ecológica (I.01) e Níveis escalonados de terraceamento amplo (I.03). Essa foi a faixa de maior presença das morfologias praiais conservadas, estruturada sobre a mais larga faixa arenosa de toda a área estudada. Ao se comparar uma imagem de satélite atual com imagens históricas, observa-se que houve expressiva progradação da linha de costa. Esta área está recebendo parte do aporte sedimentar gerado pela erosão de setores ao norte, a exemplo do 4 e 5 respectivamente.

Setor 7 - Localizada na praia de Tabuba, esta área foi classificada como de processos moderados e acelerados, com predominância do segundo. Apresenta adensamento populacional muito próximo e/ou sobre a linha de costa, agravando os processos erosivos a partir da ação das ondas sobre as construções. Foram identificados os geoindicadores Escarpas erosivas (II.02), Árvore na face de praia ou com raízes expostas (III.01), Resto de construção na face de praia (IV.01) e Obras estruturais de proteção costeira (IV.02). Notadamente, os processos erosivos desta área estão relacionados à ocupação da linha de costa, sem que houvesse respeito à morfodinâmica local.

Setor 8 - O último setor, mesmo estando próximo ao anterior, com processos avançados de erosão, foi classificado como de baixa e muito baixa tendência erosiva. Esta área está próxima à foz do rio Sapucaí, que disseca a Formação Barreiras, a pouca distância a montante, principal fonte dos sedimentos arenosos da área. Apresentou os geoindicadores Material de granulometria grossa no estirâncio e berma (II.03), Escarpas erosivas (II.02) e Presença de arrecifes e crista de berma conservada (I.02). Apresenta arrecifes que ajudam na proteção da praia dissipando a energia das ondas e seus impactos sobre a faixa de areia.

Dos 11,6 km da linha de costa de Barra de Santo Antônio, 4,1 km (35,65\%) encontram-se na categoria muito baixa de intensidade erosiva, consequentemente são áreas que não possuem construções próximas ao pós-praia e sua vegetação está conservada, o que mostra a necessidade de regulação e planejamento dos processos de ocupação, bem como a importância da fiscalização e do monitoramento ambiental dessas áreas. 
As áreas que apresentaram geoindicadores da categoria de processos avançados ocupam 2,4 km (20,38\%) da linha de costa do município, devendo, assim, serem monitoradas pelos gestores públicos. Como resultado dos processos erosivos, essas áreas acabam perdendo sua beleza paisagística e, consequentemente, turística para o município, que tem características de rota turística do estado, além dos patrimônios particulares e privados existentes, principalmente na Ilha da Crôa, que hoje possui obras de engenharia para conter a ação das ondas. O restante da linha de costa apresentou faixas intermediárias de tendência ou processos erosivos.

\section{CONSIDERAÇÕES FINAIS}

Os estudos usando como metodologia os geoindicadores para a determinação da intensidade erosiva da linha de costa mostram que esse tipo de abordagem vem sendo amplamente utilizada no Brasil. No município de Barra de Santo Antônio, litoral Norte de Alagoas, esse tipo de estudo representou uma ação pioneira; no entanto, os resultados mostram-se promissores, possibilitando a setorização e caracterização dos processos erosivos.

Assim, os geoindicadores possibilitaram o mapeamento e a setorização da erosão costeira no município de Barra de Santo Antônio em relação à intensidade erosiva em sua linha de costa, que nos últimos anos apresentou grandes variações em sua morfologia, muito por conta do mau planejamento urbano ou por sua falta, ocasionando perdas de patrimônio e, consequentemente, gastos públicos para barrar esses processos acelerados.

\section{REFERÊNCIAS BIBLIOGRÁFICAS}

Anfuso, G. et al. Coastal scenic assessment and tourism management in western Cuba. Tourism Management, Amsterdam, v. 42, p. 307-320, 2014.

Martins, K.A. et al. Determinação da erosão costeira no estado de Pernambuco através de geoindicadores. Rev. Bras. de Geom., Brasília, v. 17, n. 3, p. 533-546, 2016.

Mazzer, A.M. Proposta metodológica para análise de vulnerabilidade da orla marítima à erosão costeira: aplicação em praias arenosas da costa sudeste da ilha de Santa Catarina. Tese de doutorado em Ciências, Programa de Pós-Graduação do Instituto de Geociências, Universidade Federal do Rio Grande do Sul, 169 p., Porto Alegre, 2007.

Mota, L.S.O. \&Souza, R.M. Vulnerabilidade à erosão costeira e riscos associados à ocupação: estudo de caso do município de Aracaju/Sergipe, Brasil. Rev. Territorium, Coimbra, v. 1, n. 25, p. 89-102, 2018.

Morais, J.O. et al. Erosão costeira em praias adjacentes às desembocaduras fluviais: o caso de Pontal de Maceió, Ceará, Brasil. Revista da Gestão Costeira Integrada, Lisboa, v. 8, n. 2, p. 61-76, 2008.

Muehe, D. Aspectos gerais da erosão costeira no Brasil. Revista Mercator, Fortaleza, v. 4, n. 7, p. 97-110, 2005.

Nicolodi, J.L. Documento síntese do I Simpósio Nacional sobre Erosão Costeira. Brasília: Ministério do Meio Ambiente - MMA, 25 p., 2008. 
Souza, C.R de G. Coastal erosion risk assessment, shoreline retreat rates and causes of coastal erosion along the State of São coast, Brazil. Revista Pesquisas em Geociências, Porto Alegre, v. 28, n. 2, p. 459-475, 2001.

Souza, C.R. de G. A erosão nas praias do estado São Paulo: causas, consequências, indicadores de monitoramento e risco, in Bononi, V.L.R. \& Santos Junior, N.A. (eds.). Memórias do Conselho Científico da Secretaria do Meio Ambiente: a sintese de um ano de conhecimento acumulado. São Paulo: Instituto de Botânica - Secretaria do Meio Ambiente do Estado de São Paulo, p. 48-69, 2009.

Silva, C.F.A. da et al. Índices de vulnerabilidade à erosão das praias de Ilha de Itamaracá, litoral norte de Pernambuco, Brasil. Revista Investigaciones Geográficas, Santiago, n. 52, p. 71-82, 2016. 